\title{
Statistical Analysis of the Tensile Strength of Coal Fly Ash Concrete with Fibers Using Central Composite Design
}

\author{
Marinela Barbuta, ${ }^{1}$ Emanuela Marin, ${ }^{2}$ Sorin Mihai Cimpeanu, ${ }^{3}$ Gigel Paraschiv, ${ }^{4}$ \\ Daniel Lepadatu, ${ }^{1}$ and Roxana Dana Bucur ${ }^{5}$ \\ ${ }^{1}$ Department of Concrete Structures and Building Materials, Technical University in Iasi, \\ 43 Mangeron Boulevard, 700050 Iasi, Romania \\ ${ }^{2}$ Faculty of Textile, Leather Engineering and Industrial Management, Technical University in Iasi, \\ 29 Mangeron Boulevard, 700050 Iasi, Romania \\ ${ }^{3}$ Department of Environmental and Land Improvements, University of Agronomical Sciences and \\ Veterinary Medicine in Bucharest, Marasti 59, 011464 Bucharest, Romania \\ ${ }^{4}$ Department of Materials Engineering, University Politehnica in Bucharest, 313 Independentei, 060042 Bucharest, Romania \\ ${ }^{5}$ Livestock Building Department, University of Agricultural Sciences and Veterinary Medicine in Iasi, \\ 3 Sadoveanu, 700490 Iasi, Romania
}

Correspondence should be addressed to Roxana Dana Bucur; dbucur@uaiasi.ro

Received 28 October 2014; Accepted 26 January 2015

Academic Editor: Sridhar Komarneni

Copyright (C) 2015 Marinela Barbuta et al. This is an open access article distributed under the Creative Commons Attribution License, which permits unrestricted use, distribution, and reproduction in any medium, provided the original work is properly cited.

\begin{abstract}
The influence of coal fly ash and glass fiber waste on the tensile strength of cement concrete was studied using central composite design. Coal fly ash was used to replace $10 \%$ of the cement in the concrete mix. Glass fiber was added to improve the tensile properties of the concrete in different dosages and lengths. In total, 14 mixes were investigated, one only with $10 \%$ coal fly ash replacement of cement and the other thirteen were determined by the experimental design. Using analysis of variance, the order of importance of the variables was established for each property (flexural strength and split tensile strength). From the nonlinear response surfaces, it was found that higher values of flexural strength were obtained for fibers longer than $12 \mathrm{~mm}$ and at a dosage of 1-2\%. For split tensile strength, higher values were obtained for fibers with a length of $19-28 \mathrm{~mm}$ and at a dosage of $1-1.5 \%$.
\end{abstract}

\section{Introduction}

Currently, wastes are a major problem throughout the world, as they are stored on huge areas of land and pollute the environment. The capitalization of waste is difficult because of their variety, as well as their unknown properties over time. The building material industry is a domain of interest for wastes, as researchers have tried to produce new construction materials incorporating otherwise useless materials. Many construction materials used today are fabricated with different types of wastes such as concrete, cement, masonry block, and insulating materials $[1-5]$.

An important use for wastes is introducing them as a powder or filler in the composition of construction materials (cement, concrete, asphalt, etc.) or use as aggregates (concrete or bricks from demolition can be used as an aggregate, steel slag can be transformed into aggregates, etc.). Concrete is one type of building material that can incorporate many types of waste such as silica fume, coal fly ash, cinder, husk, tires, and glass [2, 3, 6-9].

The addition of wastes to concrete can improve or diminish some properties of the material [10]. Therefore, a combination of wastes is often used or other materials are introduced into the composition to compensate for any disadvantages. These materials can be fibers of different types or lengths (steel, glass, polyester, carbon, bore, textile, etc.) [1114] or nanomaterials (nanotubes of carbon, nanoargillaceous materials, etc.) $[15,16]$.

The present study investigated the tensile properties of cement concrete following the incorporation of coal fly ash 


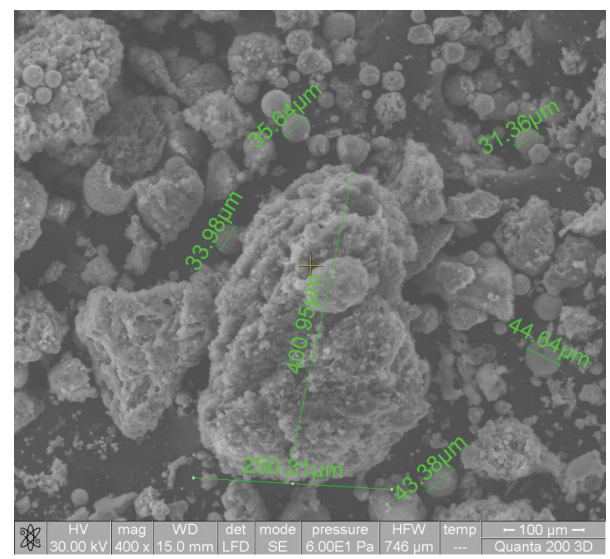

FIGURE 1: Scanning electron microscopic image of the coal fly ash from the Holboca Thermal Power Plant (magnified 400x).

and glass fiber. Statistical analysis based on central composite design was used to establish the influence of concrete components on its flexural and split tensile properties.

\section{Materials and Methods}

2.1. Materials. The experimental study was carried out on cement concrete with coal fly ash and glass fibers. To prepare the concrete, the following raw materials were used: cement, ash as a filling agent, river aggregate and gravel, and glass fibers. The cement was type CEM I 42.5, which is a Portland cement produced in Romania.

The coal fly ash (CFA) was from the Holboca Thermal Power Plant, Iasi County, Romania. The ash was an inorganic residue derived from the combustion of pulverized charcoal in the process of generating thermal energy $[17,18]$. The coal fly ash was composed of very small round particles, with amorphous glass and crystalline phases; the diameter varied from 0.01 to $400 \mu \mathrm{m}$ (Figure 1).

The principal properties of coal fly ash were gray-black color, spherical particles, specific area $480-520 \mathrm{~m}^{2} / \mathrm{kg}$, and density $2400-2550 \mathrm{~kg} / \mathrm{m}^{3}$ [18]. The coal fly ash presented pozzolanic properties, that is, a high lime binding capacity, which makes it useful in the manufacture of cement, concrete, and concrete-admixed products. The characteristics of the coal fly ash used in the experimental tests are given in Table 1.

Different lengths of glass fibers were introduced into the concrete mix in different dosages. The fiber percentages were between $0.25 \%$ and $1.75 \%$ of the concrete weight. The fiber length was between $5 \mathrm{~mm}$ and $35 \mathrm{~mm}$. The properties of glass fibers were yarn strength $72.6 \mathrm{~N}$ and loop strength $101.85 \mathrm{~N}$. The aggregate was a type of natural sand (diameter $0-4 \mathrm{~mm}$ ) and river gravel, diameters of $4-8 \mathrm{~mm}$ and $8-$ $16 \mathrm{~mm}$. A superplasticizer type Viscocrete-1040 was added to the mixture to improve its workability.

2.2. Experimental Samples. In the study of a new material, there are many factors which influence its behavior under loading and also its durability over time. The factors which
TABLE 1: Chemical properties of the coal fly ash from thermal power plant Holboca.

\begin{tabular}{lcc}
\hline & Coal fly ash & \\
Element & Wt\% & At\% \\
\hline CK & 17.15 & 26.89 \\
NK & 01.34 & 01.80 \\
OK & 37.50 & 44.13 \\
NaK & 00.69 & 00.56 \\
MgK & 00.52 & 00.40 \\
AlK & 13.09 & 09.14 \\
SiK & 18.37 & 12.32 \\
SK & 00.70 & 00.41 \\
KK & 01.74 & 00.84 \\
CaK & 03.17 & 01.49 \\
TiK & 01.71 & 00.67 \\
FeK & 04.01 & 01.35 \\
Matrix & Correction & ZAF \\
\hline
\end{tabular}

Note: Wt is mass percentage and At is the atomic number; $\mathrm{K}$ represents the layer to which the chemical properties were determined.

could influence the mechanical proprieties of concrete are presented as a fishbone diagram in Figure 2.

The mechanical properties of concrete are affected by various parameters such as the aggregate, water, cement, and additional materials. In the present study, the influence of coal fly ash and glass fiber on the tensile properties of cement concrete was evaluated. The coal fly ash content was maintained constant, $10 \%$, only the dosage and length of glass fibers were varied.

The control concrete composition was grade C25/30: cement $360 \mathrm{~kg} / \mathrm{m}^{3}$ (of which $10 \%$ was replaced with coal fly ash), diameter $0-4 \mathrm{~mm}$ in a quantity of $803.16 \mathrm{~kg} / \mathrm{m}^{3}$, diameter $4-8 \mathrm{~mm}$ in a quantity of $384.12 \mathrm{~kg} / \mathrm{m}^{3}$, diameter $8-16 \mathrm{~mm}$ in a quantity of $558.72 \mathrm{~kg} / \mathrm{m}^{3}$, water $180 \mathrm{~L} / \mathrm{m}^{3}$, and superplasticizer type Sika ViscoCrete-1040 in a dosage of $1.4 \%$ of the cement weight. Near the control mix, a number of 13 mixes were established by using a rotated centered composed program of second order, with two variables. The total number of tests was statistically established taking into account the number of independent variables, the type of analyze that was done and the type of experimental plan that was chosen. Two variables for input were chosen: length and dosage of glass fiber. The dosages of glass fibers were between $0.25 \%$ and $1.75 \%$ of the concrete mass, and the lengths were between $5 \mathrm{~mm}$ and $35 \mathrm{~mm}$. The experimental matrix contains a number of 13 experiments (13 mixes).

The concrete was prepared in a $1.0 \mathrm{~m}^{3}$ mixer by mixing the aggregates with cement, coal fly ash, and water; before the final mixing, the fibers were introduced into the fresh mix. The concrete was poured into molds of $100 \times 100 \times$ $550 \mathrm{~mm}$ and kept in water under laboratory conditions at $20^{\circ} \mathrm{C}$. The samples were tested for flexural strength and split tensile strength after 28 days [19]. 


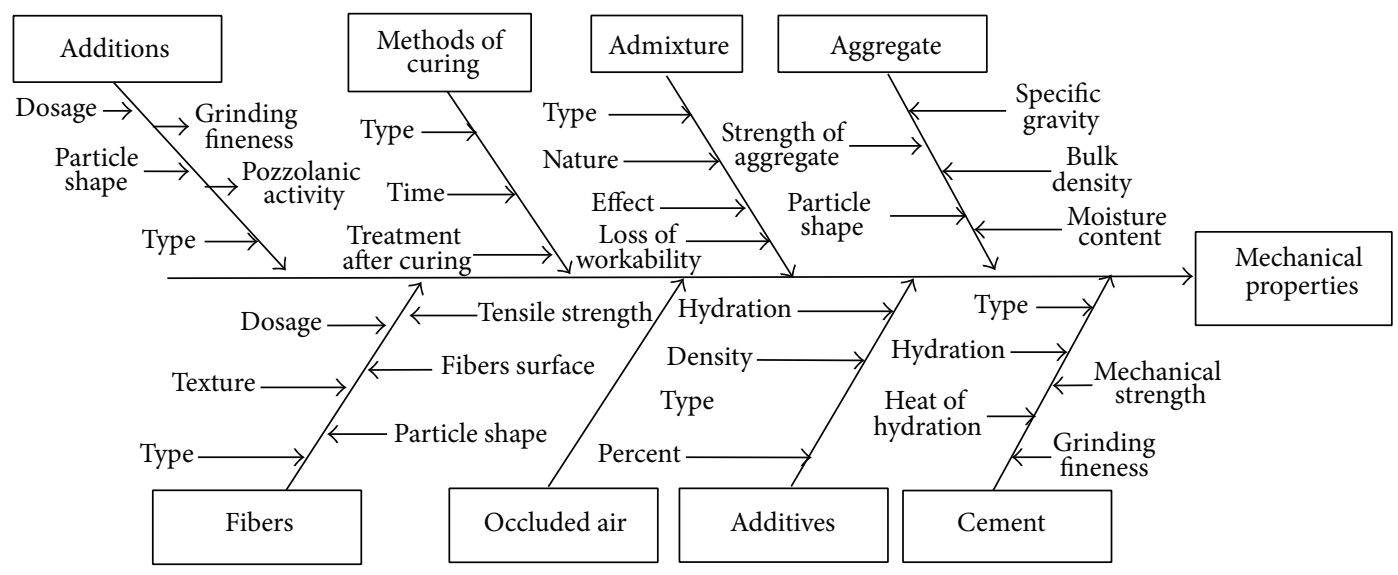

FIGURE 2: Fishbone diagram of factors affecting the mechanical properties of concrete.

2.3. Design of Experiment (DOE) and Response Surface Method (RSM). RSM consists of a group of empirical techniques devoted to the evaluation of relations existing between a cluster of controlled experimental factors and the measured responses, according to one or more selected criteria. Prior knowledge and understanding of the process and the process variables under investigation are necessary to achieve a realistic model.

RSM provides an approximate relationship between a true response, $Y_{t}$, and $n$ design variables, which is based on the observed data from the process or system. The response is generally obtained from real experiments or computer simulations, and the true response $Y_{t}$ is the expected response. Thus, computer simulations were performed in this paper. We suppose that the true response $Y_{t}$ can be written as

$$
Y_{t}=F\left(x_{1}, x_{2}, \ldots, x_{n}\right),
$$

where the variables $x_{1}, x_{2}, \ldots, x_{n}$ are expressed in the natural units of a measurement, so they are called natural variables.

The experimentally obtained response $Y_{t}$ differs from the expected value $y$ due to random error. Because the form of the true response function $F$ is unknown and perhaps very complicated, we must approximate $y$. It can be written as

$$
y=F\left(\varsigma_{1}, \varsigma_{2}, \ldots, \varsigma_{n}\right)+\varepsilon,
$$

where $\varepsilon$ denotes the random error, which includes the measurement error on the response and is inherent in the process or system.

The variables $\varsigma_{1}, \varsigma_{2}, \ldots, \varsigma_{n}$ are the coded variables of the natural variables. We treat $\varepsilon$ as the statistical error, often assuming it to have a normal distribution with mean zero and variance $\sigma^{2}$.

In many cases, the approximating function $F$ of the true response $y$ is normally chosen to be either a first-order or a second-order polynomial model, which is based on Taylor series expansion.

In general, the second-order model is

$$
y=\beta_{0}+\sum_{j=1}^{k} \beta_{j} x_{j}+\sum_{j=1}^{k} \beta_{j j} x_{j}^{2}+\sum_{i<j}^{k} \beta_{i j} x_{i} x_{j} .
$$

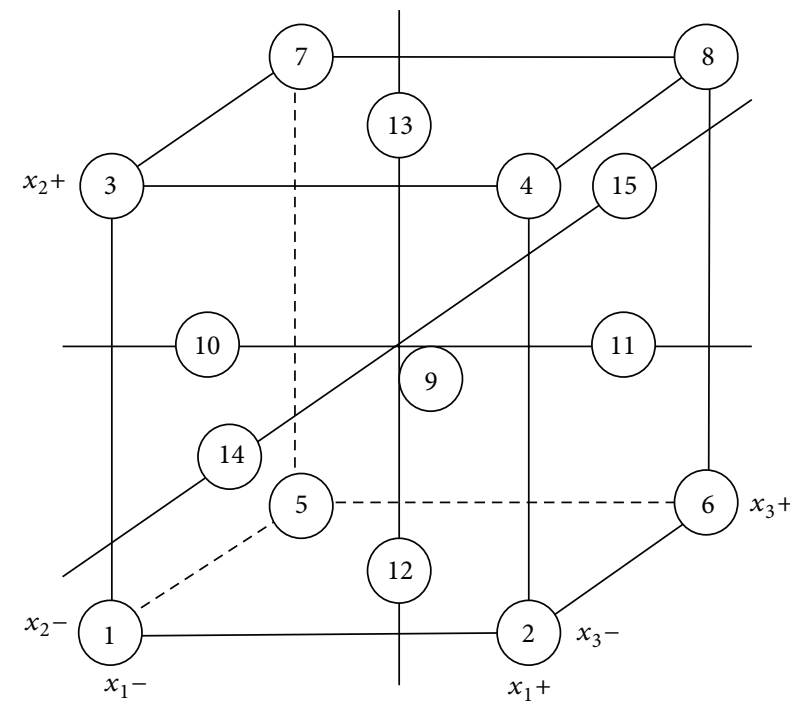

FIgURE 3: Central composite design for three factors.

In order to more accurately predict the response, the second-order model is used to fit a curvature response at this paper.

Box and Wilson [6] devised a workable alternative to the $3^{k}$ factorial system through the development of the class of composite design; this special type of experimental design is called central composite design $[6,7,14]$. Central composite design $(C C D)$ is a $2^{k}$ factorial or fractional factorial augmented by an additional axial point and center point. When $k$ is 3 , the experimental treatment of CCD is as shown in Figure 3. These eight corner points are located at the vertices of a cube, which in experiments include trials 1, 2, 3, 4, 5, 6, 7, and 8 , and are used to develop the first-order model. These experiments are extended to obtain a second-order model. Six axial points and a center point are added to the cube. This design provides five levels for each design variable. Therefore, the number of treatments is calculated by

$$
T=2^{k}+2 k+n_{0},
$$



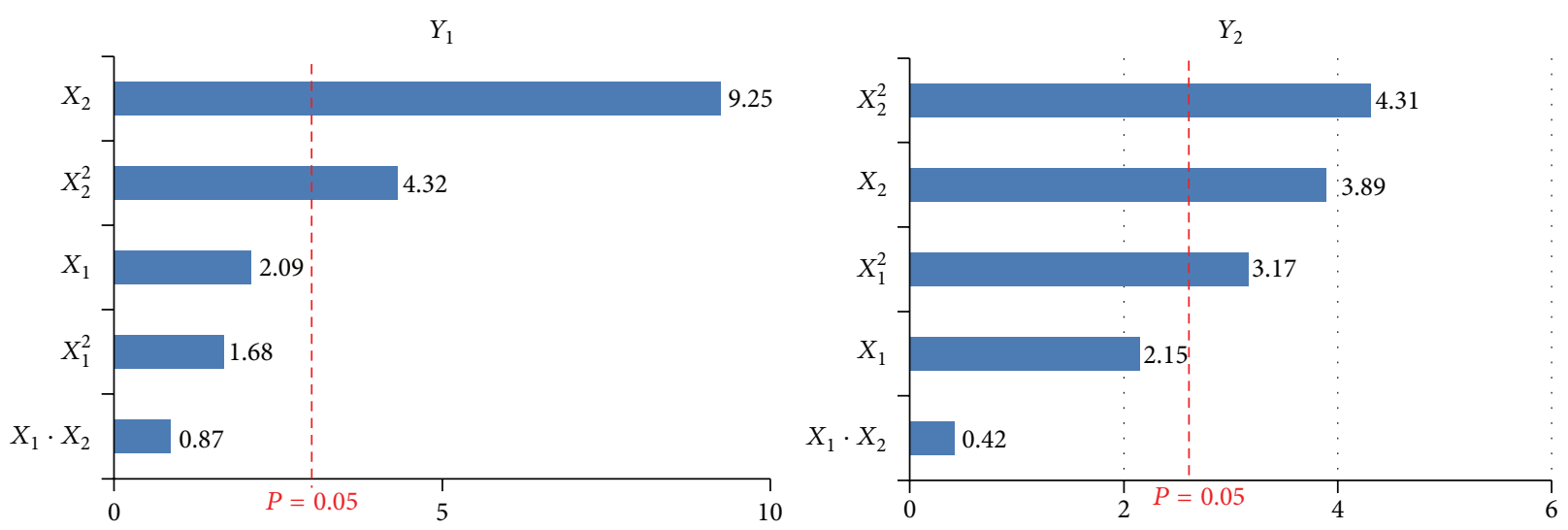

FIGURE 4: Pareto charts of $Y_{1}$ (flexural strength) and $Y_{2}$ (split tensile strength).

where $2^{k}$ is the number of experiments for the $2^{k}$ factorial design, $2 k$ is the number of axial points, and $n_{0}$ is the number of replications for the center point.

In an experiment to predict the response of a system, it is often convenient to use the coded value of a design variable, with -1 representing the low level of a variable and +1 the high level. The coded values of design variables that are obtained from the transforming equation are as follows:

$$
\varsigma_{i}=\frac{x_{i}-x_{i 0}}{d_{i}}
$$

where $x_{i}$ is natural variable (length and percentage of fibers) in their original units, $\varsigma_{i}$ is the coded value of its natural variable, $x_{i 0}$ is the natural value corresponding to the zero level, and $d_{i}$ is equally spaced between the levels of each variable.

2.4. Parameter Selection. To study the influence of concrete components on the tensile strength, 13 mixes were established by the experimental design. In addition to the 13 mixes, a control mix with only coal fly ash (which replaced $10 \%$ of the cement) was poured. After testing, the experimental results obtained for flexural strength $\left(f_{t i}\right)$, noted $Y_{1}$, and splitting strength $\left(f_{t d}\right)$, noted $Y_{2}$, in Table 3 were analyzed using central composite design. All experimentally obtained values of flexural strength and split tensile strength for cement concrete with coal fly ash and glass fibers were greater than those from the cement concrete with coal fly ash (without fibers); that is, $f_{t i}=3.09 \mathrm{~N} / \mathrm{mm}^{2}$ and $f_{t d}=3.71 \mathrm{~N} / \mathrm{mm}^{2}$. The increase in flexural strength (medium value) by adding glass fibers was about $25 \%$ and that of split tensile strength was about $20 \%$.

Table 2 shows the parameters selected for the study, that is, the length of fibers $\left(X_{1}\right)$ and glass fiber percentages $\left(X_{2}\right)$, with their real values as well as the codes used in the central composite design. Table 3 shows the design matrix in coded values.
TABLE 2: Coding of the input parameters.

\begin{tabular}{lcccccc}
\hline \multirow{2}{*}{ Parameter } & \multirow{2}{*}{ Symbol } & \multicolumn{5}{c}{ Level } \\
& & -1.41 & -1 & 0 & 1 & +1.41 \\
\hline Length & $X_{1}$ & 5 & 10 & 20 & 30 & 35 \\
Percentage & $X_{2}$ & 0.25 & 0.5 & 1 & 1.5 & 1.75 \\
\hline
\end{tabular}

TABLE 3: The design matrix in coded values of the CCD.

\begin{tabular}{lcccc}
\hline Runs & $X_{1}$ & $X_{2}$ & $Y_{1}$ & $Y_{2}$ \\
\hline 1 & 1.00 & 1.00 & 4.12 & 3.42 \\
2 & 1.00 & -1.00 & 2.54 & 2.05 \\
3 & -1.00 & 1.00 & 3.92 & 3.02 \\
4 & -1.00 & -1.00 & 2.71 & 2.09 \\
5 & -1.41 & 0.00 & 3.36 & 2.48 \\
6 & 1.41 & 0.00 & 4.18 & 4.43 \\
7 & 0.00 & -1.41 & 2.34 & 1.77 \\
8 & 0.00 & 1.41 & 4.32 & 4.21 \\
9 & 0.00 & 0.00 & 3.91 & 4.41 \\
10 & 0.00 & 0.00 & 3.98 & 4.52 \\
11 & 0.00 & 0.00 & 3.89 & 4.39 \\
12 & 0.00 & 0.00 & 3.95 & 4.45 \\
13 & 0.00 & 0.00 & 3.93 & 4.43 \\
\hline
\end{tabular}

\section{Results and Discussion}

DOE is a structured, organized method that is used to determine the relationship between the different factors $\left(X_{i}\right)$ affecting a process and the output of that process $\left(Y_{i}\right)$. This method and statistical analysis allowed us to investigate the effects of factors on the mechanical characteristics of concrete.

From the experimental tests, the maximum value of flexural strength was obtained for a fiber length of $20 \mathrm{~mm}$ and $1.75 \%$ glass fiber. The maximum value of split tensile strength was obtained for a length of fiber of $20 \mathrm{~mm}$ and $1 \%$ glass fiber (Table 3). 
TABLE 4: ANOVA of flexural strength and split tensile strength.

\begin{tabular}{|c|c|c|c|c|c|c|c|c|c|c|}
\hline & \multicolumn{5}{|c|}{$Y_{1}$} & \multicolumn{5}{|c|}{$Y_{2}$} \\
\hline & SS & $\mathrm{df}$ & MS & $F$ & $P$ & SS & $\mathrm{df}$ & MS & $F$ & $P$ \\
\hline$X_{1}(\mathrm{~L})$ & 0.18677 & 1 & 0.18677 & 4.0929 & 0.0828 & 1.26956 & 1 & 1.269 & 4.620 & 0.0686 \\
\hline$X_{1}(\mathrm{Q})$ & 0.13010 & 1 & 0.13010 & 2.8510 & 0.1352 & 2.77308 & 1 & 2.773 & 10.09 & 0.0155 \\
\hline$X_{2}(\mathrm{~L})$ & 3.90324 & 1 & 3.90324 & 85.533 & 0.0001 & 4.17901 & 1 & 4.179 & 15.20 & 0.0059 \\
\hline $\mathrm{X} 2(\mathrm{Q})$ & 0.85295 & 1 & 0.85295 & 18.691 & 0.0035 & 5.10799 & 1 & 5.107 & 18.59 & 0.0035 \\
\hline$X_{1}(\mathrm{~L})$ by $X_{2}(\mathrm{~L})$ & 0.03422 & 1 & 0.03422 & 0.7499 & 0.4152 & 0.04840 & 1 & 0.048 & 0.1761 & 0.6873 \\
\hline Error & 0.31944 & 7 & 0.04563 & & & 1.92339 & 7 & 0.2747 & & \\
\hline Total SS & 5.33507 & 12 & & & & 14.15548 & 12 & & & \\
\hline
\end{tabular}

TABLE 5: Observed, predicted, and residual values of the two responses $Y_{1}$ and $Y_{2}$.

\begin{tabular}{|c|c|c|c|c|c|c|}
\hline & \multicolumn{3}{|c|}{$Y_{1}$} & \multicolumn{3}{|c|}{$Y_{2}$} \\
\hline & Observed & Predicted & Residual & Observed & Predicted & Residual \\
\hline 1 & 4.12 & 4.390851 & -0.270851 & 3.42 & 4.238635 & -0.818635 \\
\hline 2 & 2.54 & 2.850557 & -0.310557 & 2.05 & 2.616282 & -0.566282 \\
\hline 3 & 3.92 & 3.909381 & 0.010619 & 3.02 & 3.245694 & -0.225694 \\
\hline 4 & 2.71 & 2.739087 & -0.029087 & 2.09 & 2.063341 & 0.026659 \\
\hline 5 & 3.36 & 3.414341 & -0.054341 & 2.48 & 2.523305 & -0.043305 \\
\hline 6 & 4.18 & 3.859047 & 0.320953 & 4.43 & 3.682717 & 0.747283 \\
\hline 7 & 2.34 & 2.180224 & 0.159776 & 1.77 & 1.586246 & 0.183754 \\
\hline 8 & 4.32 & 4.213165 & 0.106835 & 4.21 & 3.689776 & 0.520224 \\
\hline 9 & 3.91 & 3.918669 & -0.008669 & 4.41 & 4.404801 & 0.005199 \\
\hline 10 & 3.98 & 3.918669 & 0.061331 & 4.52 & 4.404801 & 0.115199 \\
\hline 11 & 3.89 & 3.918669 & -0.028669 & 4.39 & 4.404801 & -0.014801 \\
\hline 12 & 3.95 & 3.918669 & 0.031331 & 4.45 & 4.404801 & 0.045199 \\
\hline 13 & 3.93 & 3.918669 & 0.011331 & 4.43 & 4.404801 & 0.025199 \\
\hline
\end{tabular}

To continue the study, it was important to determine which parameter had the greatest influence on strength. This parameter was then varied to obtain higher values for the flexural strength and split tensile strength.

Analysis of variance (ANOVA) is a common method used to compare the relative strength of two related models. This method analyzes the degree to which residual variance changes with the addition of explanatory variables to the basic model. ANOVA (Table 4) gives a nonlinear response surface with the significant factor $X_{2}$ for the two responses, $Y_{1}$ and $Y_{2}$. This is shown by the value of $P$ (Table 4 ), which must be very small; that is, $P<0.05$.

Pareto charts $[6,7,14]$ obtained from the statistical analysis are presented in Figure 4, and show the importance order of the variables. Consequently, it can be seen that $X_{2}$ (fiber percentage) was the factor that most significantly influenced the response $Y_{1}$, through its linear and nonlinear components; $X_{1}$ (fiber length) did not influence $Y_{1}$. Also, $Y_{2}$ was significantly affected by $X_{2}$ (fiber percentage), by its linear and nonlinear components, and by the length of the fibers $\left(X_{1}\right)$, through the nonlinear component.

The predicted values in Table 5 were obtained by regression with an error of $0.05 \%$. The coefficient of determination, $R^{2}$, is given by $R^{2}=0.94012$, for $Y_{1}$, and $R^{2}=0.86412$ for $Y_{2}$, which indicate a good approximate for the two responses.
In this study, three-dimensional response surface plots were constructed to illustrate the effect of any two factors $\left(X_{1}, X_{2}\right)$ on the two response values $Y_{1}$ (flexural strength) and $Y_{2}$ (split tensile strength). Figure 5 illustrates the nonlinear response surface model of the length versus the percentage of fibers obtained with the Matlab program.

In Figure 6, it can be seen that higher values of $Y_{1}$ (flexural strength) were obtained for a length greater than $12 \mathrm{~mm}$ and for an incorporation percentage of 1-2\%. For $Y_{2}$ (split tensile strength), higher values were obtained for a length of $19-28 \mathrm{~mm}$ and an incorporation percentage of 1$1.5 \%$.

\section{Conclusions}

This study focused on characterizing cement concrete containing coal fly ash and glass fiber. Coal fly ash was used to replace a part of cement and glass fiber was added to improve the mechanical properties, especially the tensile strength. The statistical analysis showed that higher values of $Y_{1}$ (flexural strength) were obtained for a fiber length greater than $12 \mathrm{~mm}$ and an incorporation percentage of $1-2 \%$. For $Y_{2}$ (split tensile strength), higher values were obtained for a fiber length of $19-28 \mathrm{~mm}$ and an incorporation percentage of $1-1.5 \%$. The optimum value for both strengths was obtained with an 

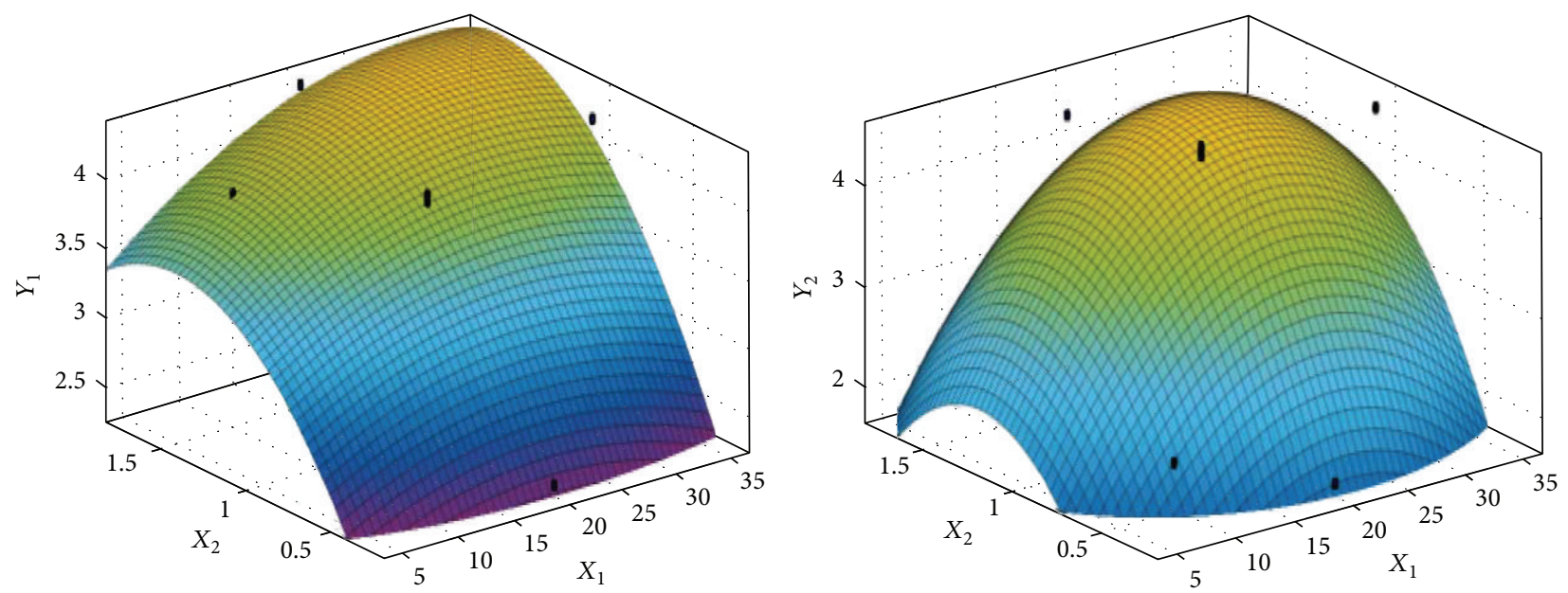

FigURE 5: Response surface for flexural strength, $Y_{1}$, and split tensile strength, $Y_{2}$.
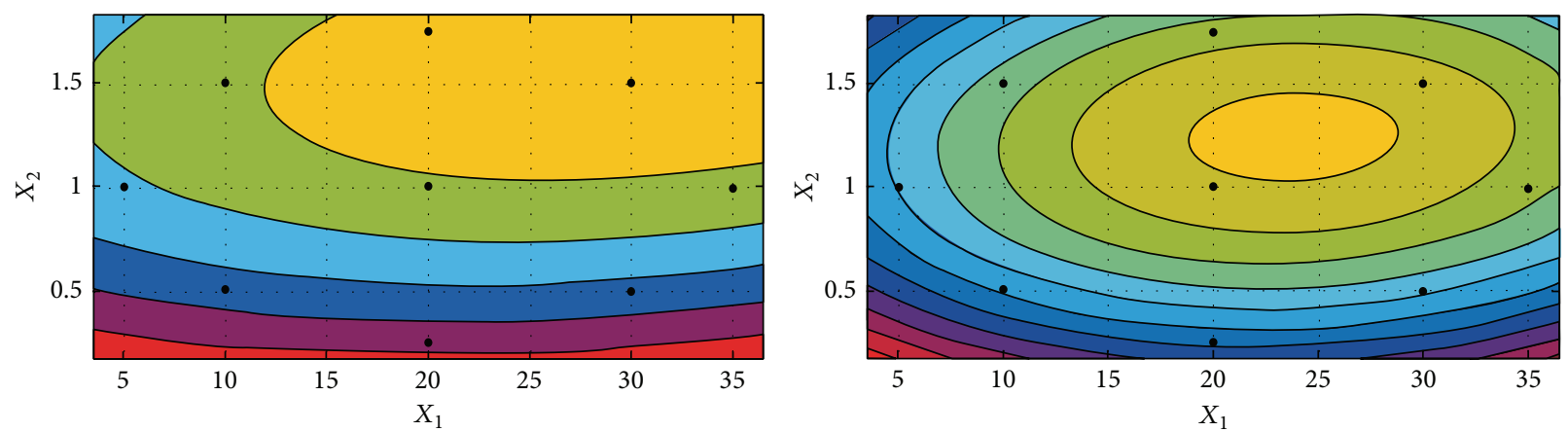

FIGURE 6: Contour plot for $Y_{1}$, flexural strength, and $Y_{2}$, split tensile strength.

incorporation percentage of $1-1.5 \%$, but not for the same length of fiber. This study showed that wastes can be used as supplements or replacements for cementitious materials, even if they do not improve all characteristics. This depends on the properties of interest, as other materials, such as fibers, can be combined to obtain useful construction materials.

\section{Conflict of Interests}

All authors declare that there is not any conflict of interests in this paper.

\section{Authors' Contribution}

All authors contributed to and approved this paper.

\section{Acknowledgments}

The authors thank the Executive Agency for Higher Education, Research, Development and Innovation Funding, Bucharest, and the Government of Romania for funding the studies under New eco-concrete to increase energy efficiency in agro-zootechnical buildings.

\section{References}

[1] S. B. Murugan, G. M. Ganesh, and A. S. Santhi, "Regression models for prediction of compressive strength of high volume fly ash (HVFA) concrete," Arabian Journal for Science and Engineering, vol. 39, no. 3, pp. 1659-1669, 2014.

[2] M. Batayneh, I. Marie, and I. Asi, "Use of selected waste materials in concrete mixes," Waste Management, vol. 27, no. 12, pp. 1870-1876, 2007.

[3] A. Benazzouk, O. Douzane, K. Mezreb, B. Laidoudi, and M. Quéneudec, "Thermal conductivity of cement composites containing rubber waste particles: experimental study and modelling," Construction and Building Materials, vol. 22, no. 4, pp. 573-579, 2008.

[4] J. Bolden, T. Abu-Lebdeh, and E. Fini, "Utilization of recycled and waste materials in various construction applications," American Journal of Environmental Sciences, vol. 9, no. 1, pp. 1424, 2013.

[5] R. P. dos Santos, J. Martins, C. Gadelha et al., "Coal fly ash ceramics: preparation, characterization, and use in the hydrolysis of sucrose," The Scientific World Journal, vol. 2014, Article ID 154651, 7 pages, 2014.

[6] G. E. P. Box and K. B. Wilson, "On the experimental attainment of optimum conditions," Journal of the Royal Statistical Society Series B, vol. 13, pp. 1-45, 1951. 
[7] A. Dean and D. Voss, Design and Analysis of Experiments, Springer, Berlin, Germany, 2000.

[8] V. K. Gupta and Suhas, "Application of low-cost adsorbents for dye removal-a review," Journal of Environmental Management, vol. 90, no. 8, pp. 2313-2342, 2009.

[9] H. Chao-Lung, B. L. Anh-Tuan, and C. Chun-Tsun, "Effect of rice husk ash on the strength and durability characteristics of concrete," Construction and Building Materials, vol. 25, no. 9, pp. 3768-3772, 2011.

[10] C. Frias, O. Frazão, S. Tavares, A. Vieira, A. T. Marques, and J. Simões, "Mechanical characterization of bone cement using fiber Bragg grating sensors," Materials \& Design, vol. 30, no. 5, pp. 1841-1844, 2009.

[11] B. W. Jo, S. K. Park, and D. K. Kim, "Mechanical properties of nano-MMT reinforced polymer composite and polymer concrete," Construction and Building Materials, vol. 22, no. 1, pp. 14-20, 2008.

[12] T. Kashiwamura, M. Shiratori, and Q. Yu, "Statistical optimization method," in Computer Aided Optimum Design of Structures, pp. 213-227, 1997.

[13] M. S. Konsta-Gdoutos, Z. S. Metaxa, and S. P. Shah, "Highly dispersed carbon nanotube reinforced cement based materials," Cement and Concrete Research, vol. 40, no. 7, pp. 1052-1059, 2010.

[14] D. C. Montgomery, Design and Analysis of Experiments, John Wiley \& Sons, New York, NY, USA, 5th edition, 2001.

[15] D. A. S. Rambo, F. D. A. Silva, and R. D. Toledo Filho, "Mechanical behavior of hybrid steel-fiber self-consolidating concrete: materials and structural aspects," Materials and Design, vol. 54, pp. 32-42, 2014.

[16] J. M. L. dos Reis, "Effect of textile waste on the mechanical properties of polymer concrete," Materials Research, vol. 12, no. 1, pp. 63-67, 2009.

[17] J. M. L. Reis and A. J. M. Ferreira, "Assessment of fracture properties of epoxy polymer concrete reinforced with short carbon and glass fibers," Construction and Building Materials, vol. 18, no. 7, pp. 523-528, 2004.

[18] I. B. Topçu and M. Canbaz, "Effect of different fibers on the mechanical properties of concrete containing fly ash," Construction and Building Materials, vol. 21, no. 7, pp. 1486-1491, 2007.

[19] B. Yesilata, Y. Isiker, and P. Turgut, "Thermal insulation enhancement in concretes by adding waste PET and rubber pieces," Construction and Building Materials, vol. 23, no. 5, pp. 1878-1882, 2009. 

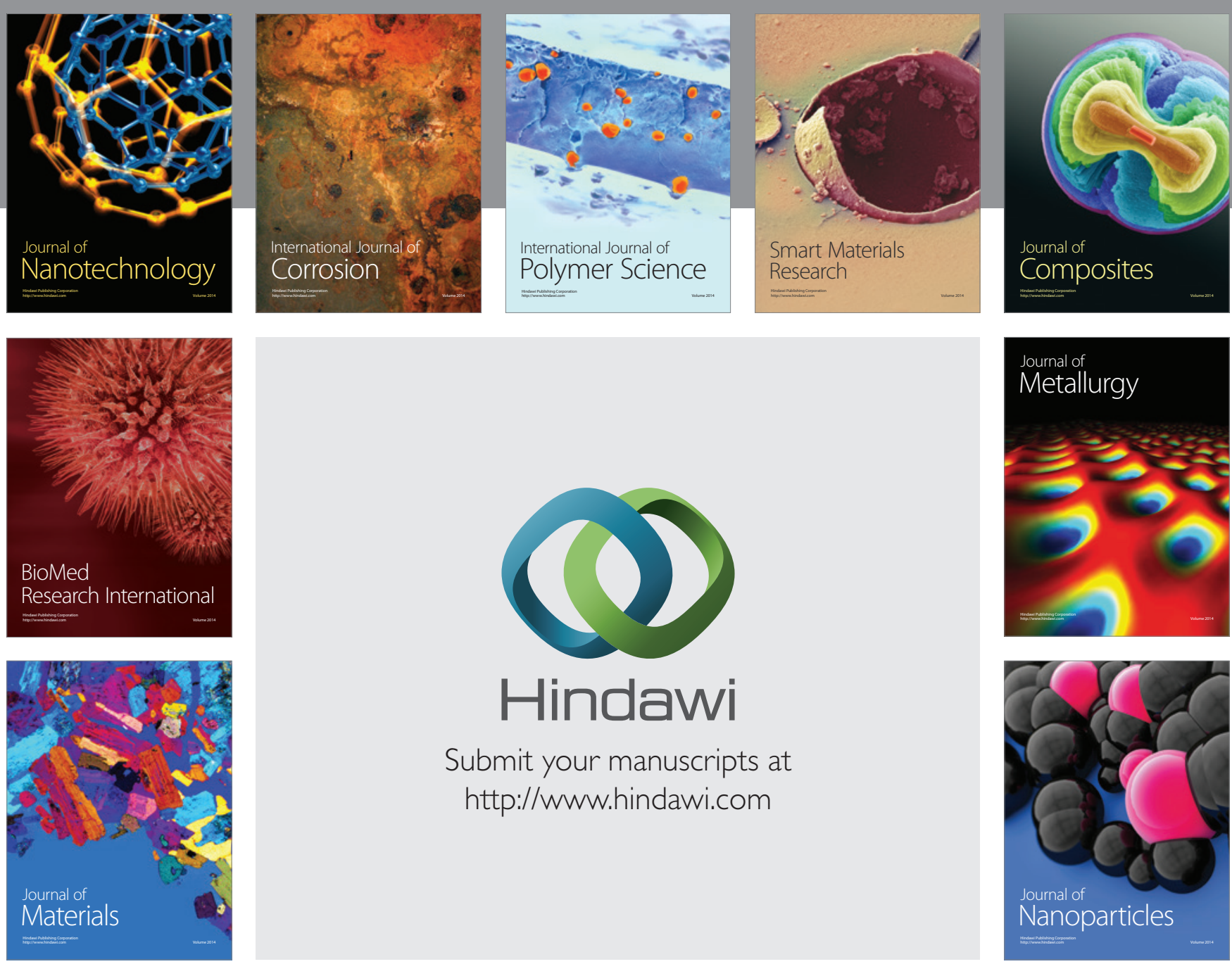

Submit your manuscripts at http://www.hindawi.com
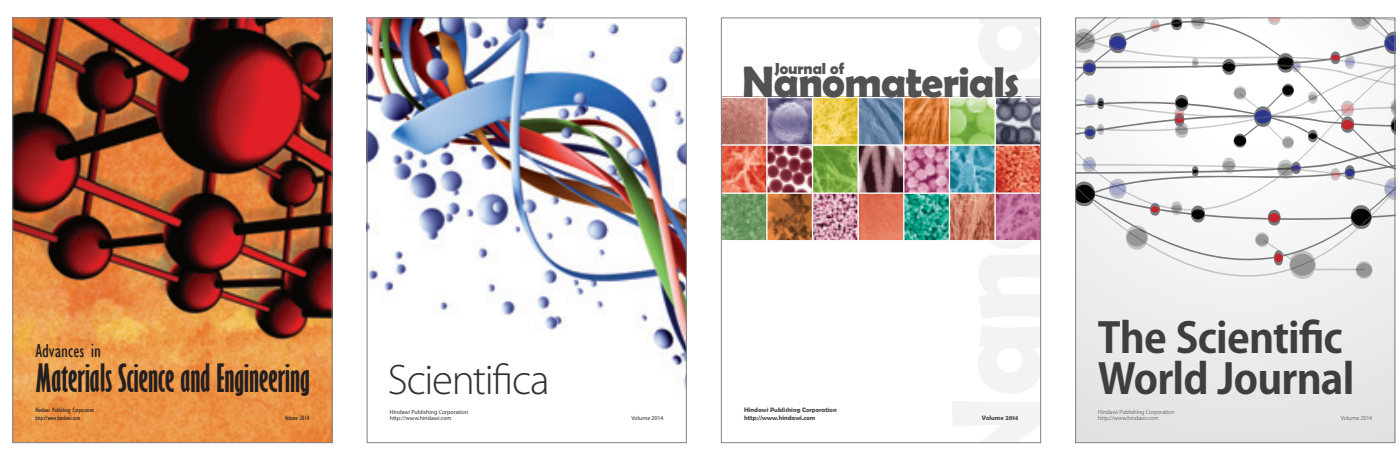

\section{The Scientific World Journal}
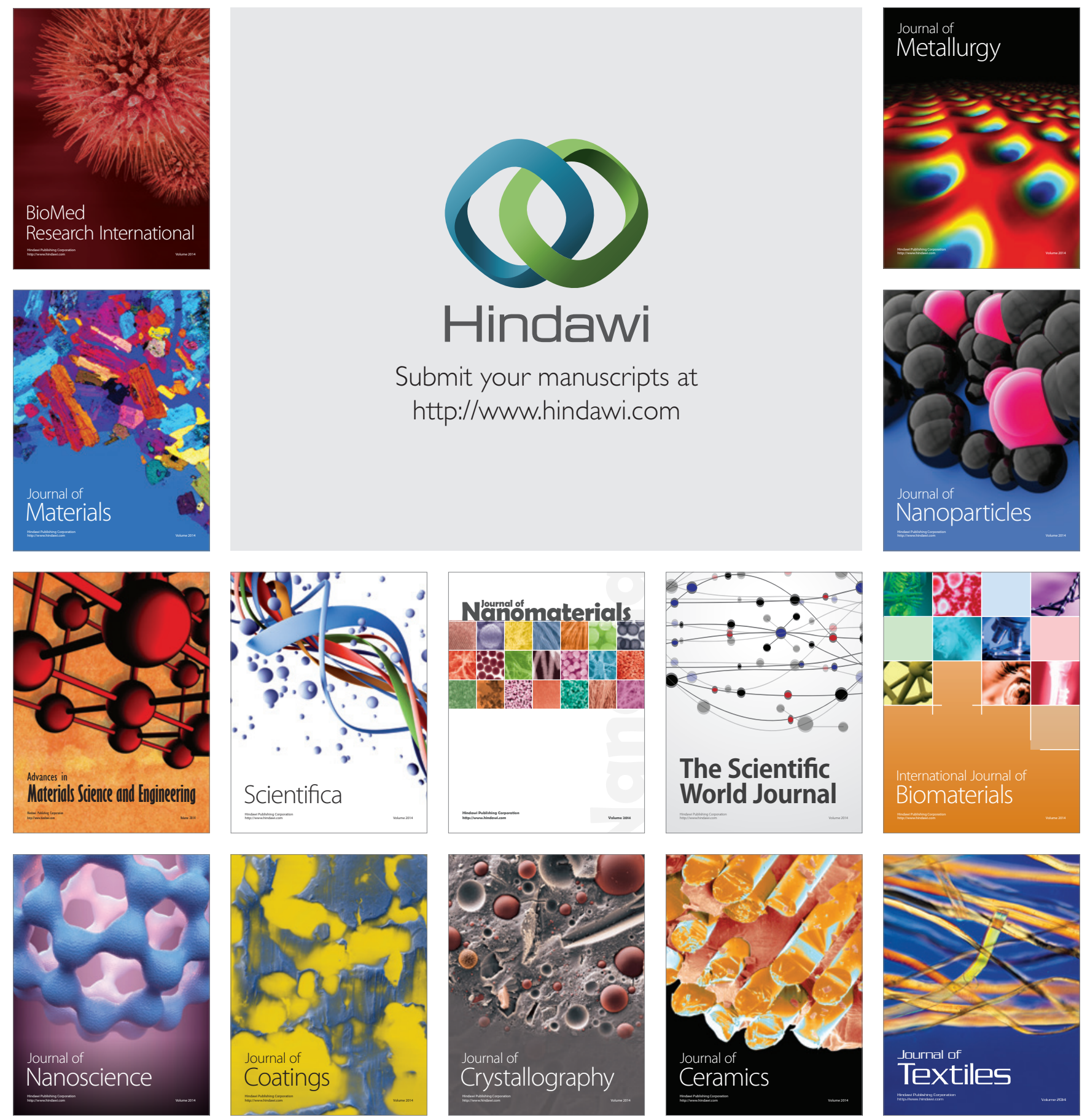